Marquette University

e-Publications@Marquette

College of Education Faculty Research and

Publications

Education, College of

$3-1-2003$

\title{
Performance of a Brief Assessment Tool for Identifying Substance Use Disorders
}

Todd Campbell

Marquette University, todd.campbell@marquette.edu

Norman G. Hoffman

Brown University

Michael B. Madson

Marquette University

Timothy Melchert

Marquette University, timothy.melchert@marquette.edu

Accepted version. Addictive Disorders and Their Treatment, Vol. 2, No. 1 (March 2003): 13-17.

Publisher Link. (C) 2003 Lippincott Williams \& Wilkins, Inc. Used with permission. 


\title{
Performance of a Brief Assessment Tool for Identifying Substance Use Disorders
}

\author{
*+Todd C. Campbell \\ The Center For Addiction and Behavioral Health Research, \\ University of Wisconsin-Milwaukee \\ Department of Counselor Education \& Counseling Psychology \\ College of Education \\ Marquette University \\ Milwaukee, WI \\ ¥Norman G. Hoffmann \\ Evidence-Based Clinical Assessments and Brown University \\ Providence, $R I$ \\ * Michael B. Madson \\ School of Education, Marquette University \\ Milwaukee, WI \\ *Timothy P. Melchert \\ Counselor Education and Counseling Psychology \\ Marquette University \\ Milwaukee, WI
}


NOT THE PUBLISHED VERSION; this is the author's final, peer-reviewed manuscript. The published version may be accessed by following the link in the citation at the bottom of the page.

Objectives: Evaluation of the performance of a brief assessment tool for identifying substance use disorders. The Triage Assessment for Addictive Disorders (TAAD) is a triage instrument that provides professionals with a tool to evaluate indications of current substance use disorders in accordance with the DSM-IV diagnostic criteria. The TAAD is a 31-item structured interview that addresses both alcohol and other drug issues to discriminate among those with no clear indications of a diagnosis, those with definite, current indications of abuse or dependence, and those with inconclusive diagnostic indications. Methods: Employing a sample of 1325 women between the ages of 18 and 60, reliability estimates and problem profiles produced by the TAAD were evaluated. Results: The Cronbach alpha coefficients for internal consistency for both the alcohol and drug dependence scales were .92. The alpha coefficients for the alcohol and drug abuse scales were .83 and .84 respectively. The diagnostic profiles elicited from the TAAD indicate that alcohol and drug dependences are the more definitive and distinct syndromes compared with the abuse syndromes. Discussion: The diagnostic profiles from this sample are consistent with previous research. The Cronbach alpha coefficients suggest that the TAAD provides an internally consistent index for alcohol and drug dependence and abuse. Implications for use in clinical practice and the need for further research regarding the psychometric properties of the TAAD are discussed.

Since the 1940s, there has been a chasm between a narrow focus on alcoholism treatment and the treatment of "other" drugs. The days of separating alcohol from other drugs in terms of treatment needs, however, has passed. It is estimated that between $20 \%$ and $43 \%$ of all substance abusers have a history of polysubstance use. ${ }^{1-3}$ That is, they have used alcohol and some other drug such as marijuana, cocaine, amphetamines, or heroin. Compared with nontreatment populations, the rate of polysubstance use is much greater for treatment populations with multiple drug use or dependence rates ranging from $50 \%$ to $90 \% .4,5$ Therefore, treatment providers and referral sources such as social service agencies need to address issues related to both alcohol and other drugs.

Identifying treatment needs is an ongoing process beginning with screening and, if indicated, follow-up with comprehensive assessment. Clinicians are encouraged to follow a decision-tree model that integrates diagnostic findings in determining treatment plans for alcohol and drug problems. ${ }^{6}$ This decision model consists of three phases: 1) screening; 2) comprehensive assessment; and 3) treatment planning. Each phase is interrelated and builds on the others, ultimately facilitating the best match between the client and the most appropriate treatment approach.

Addictive Disorders and Their Treatment, Vol. 2, No. 1 (March 2003): pg. 13-17. Publisher Link. This article is (C) Lippincott Williams \& Wilkins, Inc. and permission has been granted for this version to appear in e-Publications@Marquette. Lippincott Williams \& Wilkins, Inc. does not grant permission for this article to be further copied/distributed or hosted elsewhere without the express permission from Lippincott Williams \& Wilkins, Inc. 
Screening is defined as the "skillful use of empirically based procedures for identifying individuals who have alcohol (or other drug) related problems or who are at risk for such difficulties". ${ }^{7}$ Screens simply give a probability estimate that a given individual has or does not have a given condition. Thus, the primary objective of screening is to detect if an individual has a problem, appears to be developing one, or is not currently at any risk. This type of screening can be accomplished by using self-report questionnaires or brief interviews focusing on individuals' patterns of problems related to substance use, and/or clinical laboratory tests to detect physiological cues of excessive alcohol or other drug consumption. ${ }^{8}$

Numerous brief measures exist to screen for alcohol abuse or dependence. Two of the most widely used measures are the Alcohol Use Disorders Inventory Test (AUDIT) ${ }^{9,10}$ and the CAGE. ${ }^{11}$ Short screening instruments have also been developed for other drug abuse or dependence (e.g., Drug Abuse Screening Test [DAST]). ${ }^{11}$ Relatively few measures, however, have been developed to screen for both alcohol and other drugs (e.g., CAGE-AID, AUDIT-12; Chemical Use, Abuse and Dependence Scale). ${ }^{12-14}$ Longer screens such as the Michigan Alcoholism Screening Test (MAST) ${ }^{15}$ have the disadvantage of being lengthier but not providing more definitive information for documenting diagnostic indications according to current criteria or for covering drug as well as alcohol issues. Considering that the majority of people who are in need of treatment are polysubstance users, screening tools need to address both alcohol and other drugs. If a screening measure indicates a potential problem with alcohol or other drugs it is usually followed by a comprehensive assessment addressing biopsychosocial issues. ${ }^{16,17}$ Definitive diagnostic determinations require more extensive diagnostic tools for determining substance use disorder diagnoses in accordance with the DSM-IV. ${ }^{18,19}$ Structured interviews, such as the Substance Use Disorder Diagnostic Schedule-IV ${ }^{20}$ and the Structured Clinical Interview for the DSM IV $(\mathrm{SCID})^{21}$ can provide such definitive determinations. These determinations include both lifetime and current diagnoses for specific substances. However, these tools are lengthier, take at least half an hour or more to administer, and (in the case of the SCID) may require advanced training for the interviewer.

Addictive Disorders and Their Treatment, Vol. 2, No. 1 (March 2003): pg. 13-17. Publisher Link. This article is (C) Lippincott Williams \& Wilkins, Inc. and permission has been granted for this version to appear in e-Publications@Marquette. Lippincott Williams \& Wilkins, Inc. does not grant permission for this article to be further copied/distributed or hosted elsewhere without the express permission from Lippincott Williams \& Wilkins, Inc.. 
None of the available screens for substance use disorders document sufficient DSM-IV criteria to provide preliminary support for a dependence or abuse diagnosis. In this sense, the Triage Assessment for Addictive Disorders (TAAD) ${ }^{22}$ provides clinicians with more definitive information and greater support for identifying when a referral or definitive assessment should definitely be undertaken. In some cases, it can provide sufficient information for a preliminary current diagnosis.

In choosing a diagnostic tool, treatment and allied health care providers need to decide which constructs need to be measured, what is the purpose of the measurement, and what resources are needed to employ the measure (in terms of time, cost, training, and expertise). ${ }^{8}$ In this context, the TAAD fills a niche between the simple screen and the more comprehensive diagnostic interviews.

\section{Description of the Triage Assessment for Addictive Disorders (TAAD)}

The Triage Assessment for Addictive Disorders (TAAD) is a brief triage instrument that provides professionals with an efficient tool to evaluate current substance abuse problems in accordance with the DSM-IV diagnostic criteria. The TAAD is a 31 -item structured interview that can be administered in 10 to $15 \mathrm{~min}$, and addresses both alcohol and other drug issues. The TAAD is not intended to be a comprehensive diagnostic tool nor does it cover remission diagnoses. However, the TAAD is more than a screening tool in that it provides one of three findings:

1. the individual has significant symptoms and behaviors so that a diagnosis can be documented with little, if any, additional assessment;

2. the individual denies behaviors and events such that no diagnosis is indicated on the basis of the information; or

3. the individual acknowledges indications of a diagnosis, but additional assessment is required to make a definitive determination. ${ }^{22}$

Addictive Disorders and Their Treatment, Vol. 2, No. 1 (March 2003): pg. 13-17. Publisher Link. This article is (C) Lippincott Williams \& Wilkins, Inc. and permission has been granted for this version to appear in e-Publications@Marquette. Lippincott Williams \& Wilkins, Inc. does not grant permission for this article to be further copied/distributed or hosted elsewhere without the express permission from Lippincott Williams \& Wilkins, Inc.. 
The TAAD items are directly based on the DSM-IV diagnostic criteria. These items cover behaviors and events consistent with the criteria for abuse and dependence of alcohol and other drugs. Accurately endorsing the TAAD items consequently should lead to the reliable identification of DSM-IV substance use disorder diagnoses relative to the last 12 months.

The TAAD provides distinct profiles indicative of a dependence syndrome for either alcohol alone and for other drugs collectively. The majority of individuals who endorse items in three or more of the dependence categories present a clear constellation of problems compatible with a diagnosis of dependence. In contrast, those not meeting diagnostic criteria tend to clearly deny problems with alcohol or other drugs. ${ }^{23}$ The TAAD is currently being used in many treatment settings because of its clinical utility and ease of use. However, the psychometric properties of the TAAD need to be evaluated. The current study is a beginning to this evaluation.

\section{Methods}

\section{Procedures}

Data for this study were derived from the routine use of the TAAD in screening individuals suspected of child abuse or neglect in an eastern state. Cases were flagged for completing the TAAD if there was any mention of substance abuse in the child abuse or neglect allegation or other reason to suspect any ongoing use. An evaluation could also be requested if the child was in foster care and the mother or father was being evaluated for readiness to resume custody of the child or children. Data for this study were provided as part of an evaluation of the TAAD as part of the routine screening in the agencies. All personal identifiers were removed from the data before being sent for data entry. Unfortunately, some demographic information such as ethnicity was also purged from the individual records (agencies did not have the resources to track down the purged data). Age, gender, and education level were the only demographic variables available.

Addictive Disorders and Their Treatment, Vol. 2, No. 1 (March 2003): pg. 13-17. Publisher Link. This article is (C) Lippincott Williams \& Wilkins, Inc. and permission has been granted for this version to appear in e-Publications@Marquette. Lippincott Williams \& Wilkins, Inc. does not grant permission for this article to be further copied/distributed or hosted elsewhere without the express permission from Lippincott Williams \& Wilkins, Inc. 


\section{Sample}

The sample used for these analyses consisted of 1,325 women between the ages of 18 and 60 who were referred to social service agencies in that state during 1998-1999 for child abuse issues or neglect. The sample was drawn from those women evaluated by the organization contracted to provide the evaluation and referral service for child abuse issues or neglect for the state. The mean age of the participants for the current study was 32.32 y $(S D=7.78)$. The mean number of years of education was $11.38(S D=1.75)$ with $46.8 \%$ not completing high school.

Data regarding racial/ethnic identity was not available for this sample. However, this sample is reported by the agency to be similar to all of the clients served by this organization during these years. Although we did not have the statistics that could definitively be matched to the cohort, statistics from one quarter were available for a limited comparison to the sample used in this study. Based on data from a representative quarter (December 1997 through February 1998) 253 cases were referred for evaluation. Of these, 176 (69\%) were African American, 40 (16\%) were Hispanic, and 37 (15\%) were Caucasian. The average age was 32 and the median was 30 years of age. Most of the participants were poorly educated and on assistance at the time of the allegation of abuse or neglect. The allegations of abuse or neglect tended to be on the most recently born child. The mothers tended to have 2 to 3 children prior to the present case. The average years of alcohol or drug abuse was over 8 years. The overall demographics and other characteristics had been constant over time so that this quarter is likely to be fairly consistent with the characteristics of the sample in the current study.

\section{Scoring Algorithms}

The scoring algorithms for the TAAD were developed to classify individuals into diagnostic categories for abuse and dependence. Possible abuse is defined as a positive response to one or more items in any of the four abuse categories of the DSM-IV. Probable abuse is defined as having at least two different indications of abuse in one or more of the categories. Possible dependence is defined as having 
problems endorsed in at least three of the seven dependence criteria of the DSM-IV. Probable dependence is defined as having at least three of the criteria covered plus having positive responses on at least five different dependence items. In other words a possible diagnosis meets the minimal DSM-IV criteria, but a probable diagnosis requires a more stringent criteria so that marginal cases are excluded.

A diagnosis of dependence supercedes an abuse diagnosis. Therefore, the algorithm places individuals into the highest diagnostic category for which they qualify. For example, a classification of possible dependence constitutes a greater level of problems than probable abuse because probable dependence requires more diagnostic indications related to substance use than a probable abuse designation.

For purposes of evaluating the performance of the TAAD in this study, we are not interested in estimating population base rates. Rather, we are interested in the ability of the TAAD to provide acceptable reliability estimates and diagnostic profiles that provide differentiation among those who appear to have no diagnosis, those who have only abuse indications, and those who appear to meet dependence criteria.

\section{Results}

The Cronbach alpha coefficients for internal consistency for both the alcohol and drug dependence scales were .92. The alpha coefficients for the alcohol and drug abuse scales were .83 and .84 respectively. These statistics suggest that the TAAD provides an internally consistent index for alcohol and drug dependence and abuse. The somewhat higher coefficients for dependence would suggest that it might be the more pronounced syndrome.

For this sample, the diagnostic distributions revealed a higher relative prevalence of dependence than abuse for both alcohol and the collective drug category (see Table 1). The "possible abuse" and "possible dependence" cases met the minimal possible criteria for the respective diagnosis. For abuse, this meant the individuals met only one abuse criterion; for dependence, the possible category cases met 
only three of the dependence criteria. Those in the "probable" categories exceeded the minimal DSM-IV criteria.

The striking pattern is that individuals tend to fall into either the "no diagnosis" or "probable dependence" categories for both alcohol and drugs. The abuse categories are relatively small as is the "possible dependence" group. The problem profiles reveal that the TAAD identifies a clear dependence syndrome for the vast majority of cases who meet at least minimal indications of dependence. For abuse, we find a less definitive constellation of problems. This would be consistent with the literature that suggests that dependence is the more definitive syndrome. ${ }^{24-26}$

Of the individuals reaching a level of problems indicative of dependence, the vast majority reports criteria symptoms far in excess of the minimal diagnostic requirements. Sixty-one percent of all alcohol dependent cases (including both probable and definite) were positive on at least five of the seven dependence criteria. For drugs, $70 \%$ of the drug dependent cases were positive on at least five of the DSM IV dependence criteria. In fact, $22 \%$ of the alcohol dependent individuals and $24 \%$ of the drug dependent cases report problems in all seven of the dependence criteria.

In contrast, the majority of abuse cases are positive on relatively few of the four abuse categories. Of all alcohol abuse cases, $74 \%$ are positive on only one of the four criteria, and for drugs, $82 \%$ are positive on only one criterion. None of the abuse cases for either alcohol or drugs were positive on all four of the abuse criteria. The column labeled "Maximum" in Table $\mathbf{1}$ is formed by placing each individual into the most serious diagnostic category based on either alcohol or drugs. Almost $80 \%$ of the sample falls into the "no diagnosis" or "probable dependent" category when both alcohol and drugs are considered. The remaining $21 \%$ fall into the other three diagnostic categories.

A small proportion of the individuals with no diagnosis reported problems in two dependence criteria for either alcohol or drugs, but reported no abuse problems. These cases amounted to fewer than $6 \%$ of the total sample for alcohol and fewer than $3 \%$ for other drugs.

Addictive Disorders and Their Treatment, Vol. 2, No. 1 (March 2003): pg. 13-17. Publisher Link. This article is (C) Lippincott Williams \& Wilkins, Inc. and permission has been granted for this version to appear in e-Publications@Marquette. Lippincott Williams \& Wilkins, Inc. does not grant permission for this article to be further copied/distributed or hosted elsewhere without the express permission from Lippincott Williams \& Wilkins, Inc. 
Overall, fewer than $4 \%$ of the cases have an ambiguity of diagnosis where the individual does not appear to meet DSM-IV criteria for a diagnosis, but reports more than one indication of dependence. Fewer than $2 \%$ of the sample met only one criterion for alcohol abuse in the absence of other abuse or dependence symptoms. For drugs this percentage was $2.3 \%$. Overall, just under $3 \%$ met such minimal indications for abuse. Combining the proportion reporting problems but not meeting a diagnosis and the group meeting the most minimal criteria means that for the total sample only about $7 \%$ have serious ambiguities about whether a diagnosis is indicated.

An analogous uncertainty exists for those who technically meet abuse criteria but also endorse two dependence criteria. Since the typical dependent individual also endorses abuse indications, one might also have concerns about those who meet minimal dependence criteria without endorsing other problems. Such marginal cases concerning abuse and dependence for alcohol account for fewer than $5 \%$ of the sample. For drugs they account for a comparable proportion. When the substance categories are combined, $6 \%$ of the sample have some ambiguity between abuse and dependence for either alcohol or drugs.

In short, relatively few cases (about 7\%) had ambiguous indications of whether they might meet criteria for at least abuse. Similarly, a small minority (about 6\%) presented symptoms where there was a question as to whether abuse or dependence was the most appropriate diagnosis.

\section{Discussion}

The internal consistency reliability estimates for the TAAD obtained with the study sample are quite good. This suggests that the TAAD provides internally consistent indices for alcohol abuse and dependence and for drug abuse and dependence. In this age of accountability and need for standardized diagnostic criteria, the TAAD shows promise as an efficient and useful triage tool that can be employed in initial assessments, determining need for treatment, and making referral decisions. Because the TAAD requires only 10 to 15

Addictive Disorders and Their Treatment, Vol. 2, No. 1 (March 2003): pg. 13-17. Publisher Link. This article is @ Lippincott Williams \& Wilkins, Inc. and permission has been granted for this version to appear in e-Publications@Marquette. Lippincott Williams \& Wilkins, Inc. does not grant permission for this article to be further copied/distributed or hosted elsewhere without the express permission from Lippincott Williams \& Wilkins, Inc.. 
minutes for administration and scoring makes it attractive as a pragmatic tool for busy clinicians.

While additional study of the psychometric properties of the TAAD is needed, it can be used by clinicians in several ways. Specifically, the TAAD can be used as part of a comprehensive assessment, to standardize initial diagnostic procedures, and to assist treatment planning by providing target areas for treatment (e.g., the TAAD can help identify problem areas related to drinking such as family or legal difficulties). Programmatically, the TAAD can be used by treatment programs to help standardize clinician assessment, reduce initial diagnostic variability due to clinical judgment, and provide useful information about diagnostic populations served. This information can be used by programs to advertise services, target funding, and in program development.

The diagnostic profiles elicited from the TAAD indicating that alcohol and drug dependence are the more definitive syndromes compared with the abuse syndromes is consistent with previous research. This perspective does have theoretical implications as well as clinical implications, particularly in tailoring clinical services. For example, these findings bolster the argument that dependent individuals require more extensive and protracted services due to the greater extent and scope of problems. Conversely, briefer and less expensive services might be targeted to those confirmed as meeting abuse criteria.

While the TAAD's ability to identify and document positive dependence and abuse cases is impressive, this study was not able to definitively assess its sensitivity. It is possible that the TAAD failed to identify a number of individuals who consistently denied the problems and behaviors included in the TAAD, but still manifest a diagnosable substance use disorder. Comparisons of the TAAD findings with more comprehensive assessments, personal history, and biological tests would provide more definitive evidence of the instrument's ability to accurately identify current substance use disorders. For example, comparing the TAAD and SUDDS-IV profiles from different studies suggest that the more extensive SUDDS-IV interview detects a greater range of problems, ${ }^{23}$ but these findings were not done on identical

Addictive Disorders and Their Treatment, Vol. 2, No. 1 (March 2003): pg. 13-17. Publisher Link. This article is @ Lippincott Williams \& Wilkins, Inc. and permission has been granted for this version to appear in e-Publications@Marquette. Lippincott Williams \& Wilkins, Inc. does not grant permission for this article to be further copied/distributed or hosted elsewhere without the express permission from Lippincott Williams \& Wilkins, Inc. 
NOT THE PUBLISHED VERSION; this is the author's final, peer-reviewed manuscript. The published version may be accessed by following the link in the citation at the bottom of the page.

cases or populations, so direct comparisons have not as yet been made. Additional evaluation of the construct validity of the TAAD is also needed.

Another limitation of this study concerns the sample. The sample employed was not a randomly selected sample, but a convenience sample. Therefore the generalizability of the results to other populations may be limited. Evaluation of the reliability and validity of the data derived from the TAAD with other populations is needed to assess its utility in other populations. All psychometric properties apply to data and not to tests. ${ }^{27}$ That is, reliability and validity evidence are not characteristics of a test, but are functions of the data in hand. Researchers should always assess the psychometric properties in terms of their own data. Clinicians should do so as well. As clinical data are collected via standardized measures such as the TAAD, reliability estimates and assessment of the validity of the data can be done fairly easily with minimal consultation from researchers. Although additional study of the TAAD's psychometric properties is warranted, these results suggest that TADD provides an internally consistent measure of substance use disorders that can be useful alone as a triage tool or as part of a more comprehensive assessment in both research and clinical practice. Its brevity makes the TAAD an attractive tool for initial determinations of whether further services or assessment are warranted.

\section{First Page Author Notes}

* Marquette University

† The Center For Addiction and Behavioral Health Research

\# Evidence Clinical Assessments and Brown University

\section{References}

1. Gavin DR, Ross HE, Skinner HA. Diagnostic validity of the Drug Abuse Screening Test in the assessment of DSM III drug disorders. $\mathrm{Br} J$ Addiction. 1989;84:301-7.

2. Helzer JE, Pryzbeck TR. The co-occurrence of alcoholism with other psychiatric disorders in the general population and its impact on treatment. J Stud Alcohol. 1988;49:219-224.

Addictive Disorders and Their Treatment, Vol. 2, No. 1 (March 2003): pg. 13-17. Publisher Link. This article is (C Lippincott Williams \& Wilkins, Inc. and permission has been granted for this version to appear in e-Publications@Marquette. Lippincott Williams \& Wilkins, Inc. does not grant permission for this article to be further copied/distributed or hosted elsewhere without the express permission from Lippincott Williams \& Wilkins, Inc. 
NOT THE PUBLISHED VERSION; this is the author's final, peer-reviewed manuscript. The published version may be accessed by following the link in the citation at the bottom of the page.

3. Miller NS. Special problems of the alcohol and multiple-drug dependent: Clinical interactions and detoxification. In: Frances, R.J. \& Miller, S.I. eds. Clinical Textbook of Addictive Disorders. 2nd ed. New York: Guilford; 1998:262-288.

4. Craddock SG, Rounds-Bryant JL, Flynn PM, et al. Characteristics and pretreatment behaviors of clients entering drug abuse treatment: 1969-1993. Am J Drug Alcohol Abuse. 1997;22: 43-59.

5. Stein MD, Wilkonson J, Berglas N, et al. Prevalence and detection of illicit drug disorders among hospitalized patients. Am J Drug Alcohol Abuse. $1996 ; 22: 463-471$.

6. Frances RJ, Miller SI. Clinical Textbook of Addictive Disorders 2nd ed. New York: Guilford; 1998.

7. National Institute on Alcohol Abuse and Alcoholism [NIAAA website]. Screening for alcoholism. Alcohol Alert. April, 1990. available at: http://silk.nih.gov/silk/niaaa1publication/ aa08.htm. Accessed June 2002.

8. Allen JP, Columbus, M. Assessing alcohol problems: A guide for clinicians and researchers (NIH Publication No. 95-3745). Rockville, MD: NIAAA; 1995.

9. Saunders JB, Aasland OG, Babor TF, et al. Development of the Alcohol Use Disorders Identification Test (AUDIT): WHO Collaborative Project on Early Detection of Persons with Harmful Alcohol Consumption-II. Addiction. 1993;88:791-804.

10. Bohn M.J, Babor TF, Kranzler HR. The Alcohol Use Disorders Identification Test (AUDIT): Validation of a screening instrument for use in medical settings. J Stud Alcohol. 1994;56:423- 432.

11. Hays RD, Merz JF, Nicholas R. Response burden, reliability and validity of the CAGE, short MAST, and AUDIT alcohol screening measures. Behavior Research Methods, Instruments and Computers. $1995 ; 27: 277-280$.

12. Brown RL, Rounds LA. Conjoint screening questionnaires for alcohol and other drug abuse: Criterion validity in a primary care practice. WMJ. $1994 ; 94: 135-140$.

13. Campbell TC, Barrett D, Cisler RA, et al. Reliability Estimates of the Alcohol Use Disorders Inventory Revised to Include Other Drugs (AUDIT 12). Presented as a poster exhibit at the annual meeting of the Research Society on Alcoholism, Montreal, June 2001.

Addictive Disorders and Their Treatment, Vol. 2, No. 1 (March 2003): pg. 13-17. Publisher Link. This article is @ Lippincott Williams \& Wilkins, Inc. and permission has been granted for this version to appear in e-Publications@Marquette. Lippincott Williams \& Wilkins, Inc. does not grant permission for this article to be further copied/distributed or hosted elsewhere without the express permission from Lippincott Williams \& Wilkins, Inc. 
NOT THE PUBLISHED VERSION; this is the author's final, peer-reviewed manuscript. The published version may be accessed by following the link in the citation at the bottom of the page.

14. Dyson V, Appleby L, Altman E, et al. Efficiency and validity of commonly used substance abuse screening instruments in public psychiatric patients. J Addictive Dis. 1998;17:57-76.

15. Hedlund $\mathrm{J}$, Vieweg BW. The Michigan alcoholism screening test: $A$ comprehensive review. J Operational Psychiatry. 1984;15: 55-65.

16. Donovan DM, Marlatt GA. Assessment of addictive behaviors. New York: Guilford; 1988.

17. Murphy LL, Impara JC (eds.). Buros desk reference: Assessment of substance abuse. Lincoln, NE: Buros Institute of Mental Measurements; 1996.

18. American Psychiatric Association. Diagnostic and statistical manual of mental disorders, 4th Ed. Washington, DC: American Psychiatric Association; 1994.

19. American Psychiatric Association. Diagnostic and Statistical Manual of Mental Disorders 4th Ed. Text Revision. Washington, DC: American Psychiatric Association; 2000.

20. Hoffmann NG, Harrison PA. SUDDS-IV: Substance Use Disorder Diagnostic Schedule-IV. Smithfield, RI: Evince Clinical Assessments; 1995.

21. First MG, Spitzer RL, Gibbons M, et al. Structured Clinical Interview for DSM-IV-Patient Version (SCID-I/P, version 2.0). New York: Biometrics Department, New York State Psychiatric Institute; 1995.

22. Hoffman NG. Triage Assessment for Addictive Disorders. Smith-field, RI: Evince Clinical Assessments; 1996.

23. Hoffmann NG, DeHart SS, Campbell TC. Dependence: Whether a disorder or a disease; it is not a "concept." J Chemical Dependency Treatment. in press.

24. Grant BF. Alcohol consumption, alcohol abuse, and alcohol dependence. The United States as an example. Addiction. 1994;89: 1357-1365.

25. Hasin DS, Grant BF, Harford TC, et al. The drug dependence syndrome and related disabilities. $\mathrm{Br} J$ Addiction. 1988;83:45-55.

26. Saunders WM, Kershaw PW. Screening tests for alcoholism: Findings from a community study. Br J Addiction. 1980;75: 37-41.

27. Thompson B, Vacha-Haase T. Psychometrics is datametrics: The test is not reliable. Educational Psychological Measurement. 2000; 60:174195.

Addictive Disorders and Their Treatment, Vol. 2, No. 1 (March 2003): pg. 13-17. Publisher Link. This article is (C Lippincott Williams \& Wilkins, Inc. and permission has been granted for this version to appear in e-Publications@Marquette. Lippincott Williams \& Wilkins, Inc. does not grant permission for this article to be further copied/distributed or hosted elsewhere without the express permission from Lippincott Williams \& Wilkins, Inc. 
NOT THE PUBLISHED VERSION; this is the author's final, peer-reviewed manuscript. The published version may be accessed by following the link in the citation at the bottom of the page.

\section{Appendix}

Table 1: Prevalence of diagnostic categories as indicated by the TAAD $(N=1325)$

\begin{tabular}{lrrr}
\hline $\begin{array}{l}\text { Diagnostic } \\
\text { category }\end{array}$ & Alcohol & Drugs & Maximum \\
\hline No diagnosis & $63.6 \%$ & $53.8 \%$ & $37.4 \%$ \\
Possible abuse & $5.1 \%$ & $5.7 \%$ & $8.6 \%$ \\
Probable abuse & $4.0 \%$ & $3.2 \%$ & $5.8 \%$ \\
Possible dependence & $5.6 \%$ & $4.8 \%$ & $6.9 \%$ \\
Probable dependence & $21.7 \%$ & $32.4 \%$ & $41.3 \%$ \\
\hline
\end{tabular}

Addictive Disorders and Their Treatment, Vol. 2, No. 1 (March 2003): pg. 13-17. Publisher Link. This article is @ Lippincott Williams \& Wilkins, Inc. and permission has been granted for this version to appear in e-Publications@Marquette. Lippincott Williams \& Wilkins, Inc. does not grant permission for this article to be further copied/distributed or hosted elsewhere without the express permission from Lippincott Williams \& Wilkins, Inc.. 